\title{
M. MERLEAU-PONTY Y LOS ALCANCES DEL SILENCIO EN LA PALABRA LITERARIA. UNA REFLEXIÓN EN TORNO A LA RELACIÓN ENTRE FILOSOFÍA Y EL LENGUAJE ARTÍSTICO.
}

\author{
M. Merleau-Ponty and the Effects of Silence in Literature. \\ A Reflection on the Relationship between Philosophy and Artistic Language. \\ Gabriela Molina Ortiz ${ }^{1}$ \\ glmolina@uc.cl
}

\begin{abstract}
Resumen
Este escrito reflexionará en la visión merleau-pontiana referente a la relación entre filosofía y literatura expresada en lo que el filósofo francés concibe como el lenguaje artístico. El filósofo propondrá una alternativa al analizar la cualidad del silencio que se manifiesta en el lenguaje artístico. Por ende, indagaremos, principalmente, en las cuestiones de arte (pintura) y literatura que se observan desde su obra póstuma La prose du monde, en la cual se hace presente el desarrollo de reflexiones que consideran la importancia del lenguaje literario tanto como para la existencia como para lo que el filósofo concibe respecto al lenguaje. Desde la comprensión de las voces del silencio como lenguaje vivo, se fundamentará el nexo entre literatura y filosofía, que abrirá nuestro estudio a una reflexión en torno a la posibilidad.
\end{abstract}

Palabras claves: Filosofía, literatura, lenguaje artístico, silencio, performativo, posibilidad.

\begin{abstract}
This paper analyzes the merleau-pontian vision concerning the relationship between philosophy and literature expressed in what the French philosopher conceived as artistic language. The philosopher will proposes an alternative in the analysis of the silence that is manifested in the artistic language. We will inquire, therefore, on issues of art (painting) and literature observed from his posthumous work La prose du monde, which is a reflection that consider the importance of literary language, as well as existence, and as to what the philosopher conceives about language. From understanding the voices of silence as a living language, we will be able to see the link between literature and philosophy, which opens our study to a reflection of the possibility.
\end{abstract}

Keywords: Philosophy, literature, artistic language, silence, performative, possibility.

Fecha de recepción: 06/11/2017 - Fecha de Aceptación: 15/05/2018

${ }^{1}$ Magíster en Filosofía y Doctora (C en Filosofía por la Pontifica Universidad Católica de Chile. 


\section{Sobre ciencia, método, lenguaje artístico y literatura. Alcances iniciales en torno al análisis merleau-pontiano.}

¿Es posible hablar de un silencio en la literatura y en el lenguaje artistico? ¿Es posible una interrelación entre filosofía y literatura desde Merleau-Ponty? Para poder explorar tales preguntas, será necesario (re)concebir las cualidades del lenguaje y su relación con la filosofía. Centraremos este estudio en un análisis de las cualidades del lenguaje a la luz de la fenomenología merleau-pontiana, donde la propuesta del filósofo comienza con una reflexión básica, pero a la vez fundamental en orden al lenguaje en general, a saber, que existe una necesidad actual por la certeza, desarrollada por la garantía de efectividad con la que se percibe la ciencia, y en contraparte se instala el prejuicio hacia la supuesta subjetividad con la que se formula las humanidades [Historia, Psicología, Filosofía, etc.]. Existe actualmente una necesidad de centrar los conocimientos y los postulados dentro de un parámetro de objetividad, donde la comprobación y resultado se postulan como garantes de las más certeras verdades. Y aunque el aporte, el avance y las contribuciones de la misma son innegables, el planteamiento de nuestras líneas comprenderá las variables negativas que un exceso de objetivismo tiene para las ciencias y para filosofía, literatura y lenguaje artístico.

El filósofo francés sostiene la siguiente afirmación crítica: “La ciencia manipula las cosas, pero se niega rotundamente a habitarlas, a vivirlas. Saca de estas las cosas del mundo, la naturaleza - sus modelos internos - ciertos y certeros - para traducir su conocimiento a índices y variables permitidos por su propio método, pero que escasamente, o de tanto en tanto, se confronta con el mundo actual" (1986 9). Denuncia una falta de complicidad con el mundo, con la vida en el modo en como la ciencia manipula, sin habitar, su objeto de estudio. Así, la manipulación a nivel utilitario, aleja a la ciencia de la experiencia de lo estudiado, negándose así a habitar y a vivir aquello que es su objeto de estudio. La naturaleza y el mundo, por ende, corren el riesgo de ser objetos útiles de investigación, macromodelos que se transforman en simples garantes de postulados, con la finalidad de tener control por sobre lo que nos rodea, modelos que finalmente se convierten en premisas de absoluta certeza. Estas cualidades de la ciencia una suerte de pensamiento de sobrevuelo, - sobrevolando y no habitando el mundo - un pensamiento del objeto en general. La reflexión merleau-pontiana en L'Oeil et l'esprit (1964) nos señala que es necesario que el pensamiento científico - refiriéndonos a la ciencia más estricta referente a resultados concretos o de aquellos discursos que basan su argumentación sólo en el método científico de comprobación - se vuelva a situar en un hay previo, en el suelo del mundo sensible y del mundo trabajado, tal como está situada la vi- 
da, tal como está para nuestro existir. Así, sólo este hay previo puede hacer retornar nuestra vista a lo vital (Merleau-Ponty 1986 11).

Esta necesidad denunciada por Merleau-Ponty la podemos encontrar en lo que respecta al trato con el lenguaje, como, por ejemplo, en el modo con el cual el filósofo concibe el auge de la lingüística y la gramática. Advierte que debe existir un cuidado frente a la visión positivista y empirísta en torno a la lingüística, donde se recalca una visión y una reflexión en torno a poder perfeccionar el lenguaje en el mayor grado posible. En esto estamos presenciando un riesgo concreto, ya que, si sólo se considera el lenguaje desde esta perspectiva, se acota el mismo a un mero medio o instrumento de comunicación. Por ende, el anhelo de crear un sistema signos que tendrían un sentido universal válido para todos, ${ }^{2}$ se convertiría en una contradicción, ya que este sistema universal sería una limitante del propio lenguaje, en donde el establecimiento de la universalidad no permitiría el paso a otras significaciones posibles de un término, ni posibilitarían la variabilidad, por ejemplo, que los idiomas y las culturas se permiten en sus propias lenguas y en sus palabras. Exploremos brevemente una consecuencia inmediata de esta posibilidad: aquel quien hable, así como aquel quien hace ciencia del lenguaje, debería construir su reflexión dentro de este parámetro de efectividad universal que toma como modelo el método científico, ${ }^{3}$ y que no permitirá el paso o la reflexión en aquello que pueda ser efectivo o posible fuera del método. Por lo tanto, las variables de lo posible en la literatura serían consideradas como irrelevantes para los estudios exactos en torno al lenguaje. El filósofo francés denuncia síntomas sobre esta cuestión en las primeras páginas de La prose du monde. Establece una clara mención a lo científico, proponiendo una relación entre el concepto de algoritmo y el lenguaje, donde nos señala:

[...] el algoritmo atribuye a unos signos escogidos unas significaciones definidas a propósito y con toda precisión. Fija un cierto número de relaciones transparentes; instituye, para representarlas, símbolos que por sí mismos no dicen nada, que por tanto no dirán nunca más que lo que se ha convenido hacerles decir. Habiéndose sustraído así a los deslizamientos de sentido que dan origen al error, en principio se halla seguro de poder, en cada instante, justificar completamente sus enunciados recurriendo a las definiciones iniciales. Cuando se trate de expresar con el mismo algoritmo relaciones para las que no está hecho o, como suele decirse, problemas «de otra forma», tal vez sea

\footnotetext{
${ }^{2}$ Esto nos presenta una primera limitación: encerrar el lenguaje solamente al habla, a la comunicación por la palabra dicha, la literalidad o, desde la perspectiva merleau-pontiana, a puro signo.

${ }^{3}$ En detalle, la referencia mencionada surge de la lectura de la primera sección de La pose du monde, Merleau-Ponty dedica una detallada argumentación y comentario respecto a las cualidades científicas - como el método, cálculo, fórmula, objetividad, etc. - que predominan en la base argumentativa de los discursos actuales. (cf. Merleau-Ponty 1971 15, 54)
} 
necesario introducir nuevas definiciones y nuevos símbolos. Pero si el algoritmo cumple su oficio, si quiere ser un lenguaje riguroso y controlar a cada momento sus operaciones, es preciso que no se haya introducido nada implícito, que las relaciones nuevas y antiguas formen, juntas una sola familia, que se las vea derivar de un solo sistema de relaciones posibles, de suerte que no se dé nunca exceso de lo que se quiere decir sobre lo que se dice o de lo que se dice sobre lo que se quiere decir, que el signo siga siendo simple abreviación de un pensamiento que en cualquier momento podría explicarse y justificarse por entero (Merleau-Ponty 1971 27).

Desglosemos estas líneas; parte desde comprender una contemporaneidad del pensamiento que sustrae el lenguaje a un algoritmo o, como habíamos señalado anteriormente, a un proyecto de lengua universal, con parámetros y métodos de significación que derivan de la misma relación estricta entre signo y significado (Merleau-Ponty 1971 27, 28). En este sentido podemos medir los siguientes riegos: fijando un número determinado de significados de un término, este limita al mismo, por lo cual se corre el peligro de permanecer en interrelaciones de términos que finalmente no dirían nada, o que nada pueden decir. Se explora además la relación de necesidad de la metodología por el orden, por la seguridad de los enunciados y el terror por el error, fundando así la necesidad de concebir principios que se hallen seguros de poder justificarse completamente. Este algoritmo del lenguaje tiene por objetivo la rigurosidad del mismo, fundándola como una unidad inalterable respecto a los significados posibles, o sea como un solo sistema de relaciones posibles. Este tipo de algoritmo no puede excederse a sí mismo, por lo que no puede haber nada más allá de lo que se quiere decir, o de lo que se está diciendo en concreto. Sólo así puede este algoritmo justificarse por completo, ser absolutamente invariable y certero.

La lingüística, por ejemplo, como ciencia que estudia los variados componentes y significados dentro del lenguaje, produce una diferenciación y delimitación irreconciliable entre habla y escritura. Desde este respecto Merleau-Ponty es categórico: Encerrar el lenguaje en lo que respecta a una ciencia positiva de reglas de la lengua con una funcionalidad específica o a una mera gramática pura es tratar de sostener y hacer reposar sobre sí misma una lógica del lenguaje. Esto se puede percibir, por ejemplo, en la reducción del lenguaje a juicios lógicos como sistemas cerrados de signos delimitados que alcanzarían por sí mismos su propia función, y que limitarían las significaciones posibles. Y el riesgo es aún mayor si se limita, dentro del mismo respecto, a la filosofía. La reflexión filosófica no puede ser solamente el paso de un mundo confuso e inconexo a un universo de significaciones cerradas, sino que más bien, comienza por la conciencia de lo que roe y hace saltar, y también renueva nuestras significaciones adquiridas (Merleau-Ponty 1971 43). El lenguaje, así como la filosofía, se plantean como una cuestión de vitalidad, 
una cuestión existencial, donde el lenguaje no sólo se habla o se escribe, sino que inicialmente se vive. Por ende, debemos comprender primariamente que, una seguridad de un sistema lógico del lenguaje nos cuesta la posibilidad de lo que el filósofo francés presenta como la experiencia originaria del lenguaje ${ }^{4}$, o sea el lenguaje vivo. Esta problemática es la base general con la cual se hace manifiesta la reflexión del arte y la literatura desde la filosofía merleau-pontiana. Textos como La doute de Cézanne, $(1996$ 13, 33) o Signes (2001) presentan un trasfondo reflexivo que no se deja llevar por una argumentación absolutamente objetiva, y que da paso a la oportunidad filosófica de poder introducirnos en las cuestiones artísticas desde la vereda del arte como fenómeno expresivo. ${ }^{5}$ Así el lenguaje vivo al que se referirá el filósofo nos permitirá la posibilidad de analizar la voz del silencio. ${ }^{6}$

En primera instancia podemos ver la tensión entre lo que se considera la objetividad de una prosa filosófica que se autolimita, ${ }^{7}$ que se construye desde la certeza y que, a su vez, no se abre a explorar las variantes de las posibilidades de la condición humana. Sin embargo, pareciera que la prosa literaria y el arte literario en general poseen una capacidad única para (re)presentar el mundo y las acciones humanas. El interés merleau-pontiano por la lectura de textos de literatura pertenecientes al realismo literario francés de la segunda mitad del siglo XIX, - con sumos exponentes como por ejemplo Stendhal y Balzac - representa una base fundamental para entender la referencia a la cualidad de lenguaje vivo que le atribuye al lenguaje literario.

Ahora bien, la representatividad del realismo literario francés que analiza Merleau-Ponty, no sugiere sólo una dimensión puramente duplicativa, en el sentido de que la literatura analizada sea solamente un reflejo exacto y preciso de la realidad de una época. Al comprender la relevancia del realismo literario francés

\footnotetext{
4 "[...] La palabra "tiene" su propio sentido, el poder de significar o interpretar, porque se encuentra fundada en la experiencia corporal del mundo. Si la percepción es ya expresión, comprensión inmediata de sentido, lo es porque lo propio de la experiencia humana es ser una experiencia de lenguaje en la que el hombre mismo se vive como palabra: no hay un sujeto o pensamiento del lenguaje, sino que es el propio cuerpo el que habla." (Gamboa 2005 127).

${ }^{5}$ Merleau-Ponty (1996 23) señala: "L'artn'est ni une imitation, ni d'ailleurs una fabrication suivant les vœux de l'instinct et du bon goût. C' est une opérationd'expression."

${ }^{6}$ En lo referente al análisis de la cuestión del silencio nos referiremos a principalmente a dos textos, en orden a nuestro análisis. Primero en La prose du monde (1969), y segundo, en el ensayo titulado Le langage indirect et les voix du silence, en Signes (2001)

7 Para el filósofo el lenguaje del crítico - por ejemplo, el crítico de arte o el crítico literario - y sobre todo el lenguaje del filósofo, tiene la ambición de tratar de convertir en certeza este asidero resbaladizo que nos ofrece la literatura en torno a la experiencia ( $c f$. Merleau-Ponty 1971 141).
} 
no se busca el anhelo de una copia exacta de una sociedad determinada, ni representa sólo lo bello de las acciones del hombre, sino que más bien, y esta es una de las grandes cualidades de la literatura reflexionada por Merleau-Ponty, se centra en analizar que lo relevante de la literatura radica en hacer experimentar al lector todas las variables del mundo de la vida - aspectos buenos y malos, cualidades negativas y positivas, experiencias bellas y oscuras - un mundo donde todas las imperfecciones del hombre y la sociedad son posibles y del cual el lector se hace parte y presente. No es una representación de la mejor existencia posible, sino que más bien, de todo lo posible a la existencia. Y es ahí donde las consideraciones más estrictas en torno al lenguaje como ciencia se escapan. Así, Merleau-Ponty nos habla en La prose $\mathrm{du}$ monde de un asidero resbaladizo que nos es ofrecido por la literatura en lo referente a la experiencia o a este mundo de la vida. Así se hace necesario el siguiente ejercicio filosófico: comprender que existen cuestiones que escapan a la pura certeza, que escapan a la palabra como mero signo, pero que existen. Es un asidero resbaladizo porque en muchos momentos nos entrega más dudas que respuestas, pero además es uno de los sustentos básicos para explorar un lenguaje literario.

Sin embargo, la propuesta del filósofo no se limita a constituir diferentes tipos de lenguaje, o maneras de identificar el modo correcto con el cual abordar el lenguaje (ya que esto sería volver exponer un método acotado) sino que la lucidez merleau-pontiana contempla que, ya sea desde la vereda de la prosa científica, filosófica, literaria, artística, etc., existe una validez y relevancia del lenguaje común. A cada momento nos movemos en palabras comunes con quienes nos rodean. El hecho natural es innegable; somos parte de una comunidad que habla un idioma en específico, que se expresa en una serie de convenciones lingüísticas, ya sea el idioma en común o los modismos de un determinado pueblo. Sobre esta idea de convencionalismo se basa Merleau-Ponty para referirse a una diferenciación primaria entre dos tipos o dos modos del lenguaje que habla [parolé]: A.) El lenguaje hablado, adquirido y convencional, en tanto aquel lenguaje del que disponemos en lo cotidiano, y B.) el lenguaje hablante, aquel lenguaje que nos desliza de la constitución del mero signo, hacia el sentido de lo hablado ${ }^{8}$. Esta diferenciación estructural merleau-pontiana no tiene como objetivo presentar dos modos absolutamente distintos para concebir el lenguaje, ni produce una diferenciación entre tipos lenguajes radicalmente diferentes, sino que más bien, el trasfondo reflexivo de esta diferenciación estructural radica en concebir que ambos modos se encuentran profundamen-

\footnotetext{
${ }^{8}$ En orden a nuestro escrito, y siguiendo la idea merleau-pontiana primaria, la estructuración diferencial entre estos dos tipos de lenguaje es puramente estructural (cf. Merleau-Ponty 2006 50, 51).
} 
te unidos. No se da cabida a una diferenciación más que puramente teórica. Es aquí donde el pensamiento merleau-pontiano marca una sección de su originalidad, a saber, comprender la relevancia del lenguaje en común y convencional, y no sustraer el mismo sólo a palabrería carente de importancia. Lo que además congenia con la idea de un lenguaje vivo, un lenguaje que se expresa existencialmente. No puede haber lenguaje convencional, o hablado, que carezca de significado o lenguaje hablante y viceversa. Ninguno puede prescindir del otro en la comunicación ni en el lenguaje vivo. Es, por ende, esta cuestión, esta cualidad unificada del lenguaje la que hace posible lo que estamos señalando como la visión merleaupontiana del lenguaje artístico. Así, nuestro análisis se enfoca en reconocer que el lenguaje literario que se manifiesta en una unidad significante compuesta por la necesidad de la comunicación hablada, que se abre a la posibilidad de deslizarnos hacia sentidos y significados que se nos permiten experimentar en la obra literaria. Por ende, la clave se hace presente del siguiente modo: desde la propuesta merleau-pontiana el lenguaje se comprende como una unidad significante, lo que se atribuye como el modo originario del lenguaje, sobre este respecto cito:

El lenguaje nos lleva a las cosas mismas en la exacta medida en que, antes de tener una significación, es significación. Si no se le concede más que su función segunda, es porque se da por supuesta la primera, se le suspende de una conciencia de verdad cuyo portador es él en realidad y, en fin, se pone el lenguaje antes del lenguaje" (Merleau-Ponty 1971 40).

Este lenguaje vivo, originario, se da en unidad. Esta unidad es la que nos hace posible el contexto significativo de lo artístico. Y a su vez, esta unidad del lenguaje permite un suelo en común que sustenta la posibilidad de la transmisión de un mensaje, y la amplitud receptiva del mismo. Más aún, Merleau-Ponty no diferencia en una parte activa en el mensaje artístico (por ejemplo, el creador de la obra) y una parte pasiva que recibe el significado (el espectador o lector) sino que, para el filósofo francés, ambas partes funcionan activamente en el lenguaje artístico. Abordaremos entonces como ambas partes, necesarias y activas, no pueden subsistir sólo por sí mismas.

\section{Sobre la literatura como experiencia. Abriendo la posibilidad de un lenguaje vivo.}

Desde Merleau-Ponty podemos establecer dos principios básicos para nuestro análisis: Primero, la radical importancia del arte y la literatura no se funda en los derivados objetivos y críticos que podemos desprender de una lectura metódica de la misma. Y segundo, que si hemos de establecer una definición general de arte y lo literario, diremos, desde el filósofo francés, que es la expresión de una realidad pre- 
objetiva, ya que la comprensión de la obra y nuestra interiorización en la misma, no se produce sólo porque estemos en condición de recordar datos, palabras precisas, hechos de la narración o de representarnos determinados acontecimientos de la misma, sino porque somos capaces de percibir en la narración una [nueva] forma de ver el mundo, la sociedad, al hombre o la existencia. Lo fundamental de la literatura, desde la vereda merleau-pontiana, proviene de comprenderla como una forma de arte expresiva que es capaz de otorgarnos una experiencia vital. Los lienzos pintados, las novelas, los poemas, etc., presentan todo su relieve y complejidad en el fenómeno de la expresión, ellos mismos son expresión, son obra (MerleauPonty 1971 97). Así mismo, vemos como la literatura no se aleja de la existencia del hombre, y más aún, es capaz de moverse con fuerte lucidez dentro de las acciones humanas. Esto conlleva a que sea apto de considerar las más diferentes y posibles experiencias que se desarrollan en el mundo de la vida. Es por esto que la palabra literaria no acota su sentido en lo dicho o en lo demostrable, ya que la literatura siempre se encuentra instalada en un sentido de horizonte interpretativo.

Aquí se hace patente la relevancia de la palabra hablada y hablante, ya que, partiendo de signos convencionales (como un idioma, los modismos, una época con sus falencias y virtudes, la cultura de la época, etc.) podemos involucrar la misma vida en la lectura. Así se construye un ejercicio viviente del habla en la obra literaria, y este sentido vivo se funda en la posibilidad de su significación. Esta cualidad del lenguaje nos permite pasar de un sistema de signos de líneas escritas o palabras, hacia encontrarnos como espectadores performantes de una obra, haciendo posible un acceso a los diversos sentidos que se abren en la forma literaria. No es exagerado señalar que una de las grandes cualidades de la obra literaria, desde la perspectiva merleau-pontiana, se constituye en la habilidad de la literatura para poder habitar los más complejos rincones de lo posible en la existencia.

Sin embargo, esto abre una nueva pregunta: ¿podemos afirmar, desde esta reflexión, la idea de que una obra literaria o de arte se puede interpretar sólo de manera subjetiva y arbitraria? Se podría señalar que el lenguaje literario, al hacernos partícipes de una experiencia vital, esta experiencia sólo se remitiría a la interpretación de un sujeto en concreto, y se diferenciaría de cualquier otro tipo de experiencia referente o mencionada en la misma obra literaria. Así el espectador podría otorgar cualquier tipo de significado o sentido a la obra de la que es participe, $\mathrm{y}$, por ende, un texto o una obra artística podrían significar algo determinado para un espectador o lector y contener otra significación totalmente diferente para otro, lo que sin duda abre la posibilidad de poder postular cualquier interpretación, hasta la más irracional, respecto de la obra. Pero, por el contrario, la reflexión merleaupontiana en torno al lenguaje artístico nos remite primariamente a un lenguaje que 
se abre a la amplitud de sus significaciones posibles, pero comprendiendo a su vez que la obra artística contiene una intención de la cual autor y espectador se hacen cómplices; o sea se descarta de plano que el sentido de una obra quede remitido a una categoría interpretativa absoluta por parte del lector, donde el autor no tiene ni la más mínima inferencia en el sentido posible de su obra. El filósofo francés señala que entre autor/lector existe un interpelar y una dirección de la mirada otorgada por parte del autor, que dirige la mirada del espectador a los posibles espacios interpretativos, y que hace que una obra esté en constante diálogo con su propio sentido. Por lo tanto, también es relevante el uso del término diálogo, ya que tampoco cabe reducir una obra literaria [o artística] a un solo sentido posible, sino que más bien dentro de la dirección y de la interpelación que propone el autor de su obra, el espectador aporta desde la experiencia de la misma a una constante retribución a los sentidos posibles en la obra, y en consecuencia el espectador puede ver la relevancia de una sección de la obra artística que otro espectador puede pasar por alto y así sucesivamente. Por ende, la visión del filósofo francés entra en conflicto con la crítica artística, ya que señala que la visión del crítico, de arte o literario, presenta una visión reducida y acotada del sentido de la obra, pretendiendo imponer la importancia de una significación específica, de una mirada y de una interpretación, por sobre otras.

La literatura, por consiguiente, se transforma en un acto de complicidad y también de retribución. Ahora bien, y para complementar lo señalado anteriormente, cabe decir que el diálogo entre la obra y el sentido encarnado de la misma tiene la cualidad de poder ser además un diálogo silencioso. Esto se explica desde la reflexión de Merleau-Ponty cuando analiza en Le langage indirect et les voix du silence (2001) el lenguaje artístico, ejemplificándolo de la siguiente manera en la pintura:

La obra consumada no es, pues, la que existe en sí como una cosa, sino la que espera su espectador, lo invita a retomar el gesto que la ha creado y, salvando los intermediarios, sin otra guía que un movimiento de línea inventada, un trazo casi incorpóreo, a reencontrar el mundo silencioso del pintor, en adelante proferido y accesible (Merleau-Ponty 2006 59).

La significación y el sentido se abren en este mundo silencioso e interpretativo. Sin este silencio, el lenguaje literario no diría nada. La obra artística entonces radica en ese silencio que se presenta en el fondo de una acción, o sea aquello en donde no encontramos palabras para explicarlo; tal carencia de explicación no conduce a una carencia de sentido, sino que nos dirige a la apertura del mismo. Por ende, Merleau-Ponty nos propone que este silencio tiene una voz, nos propone algo, nos dice algo de la obra y nos conduce a los aspectos que, como silenciosos parecieran se- 
cretos, pero que en la obra se hacen accesibles y por lo tanto proferidos por los mismos artistas. Esto es lo indecible para la obra, así como también las sensaciones a las cuales la obra nos transporta. Es un caminar incesable, una palabra no dicha, un gesto que, tal vez, se lee rápidamente en la sucesión de hechos de una lectura literaria, pero que sin decirnos nada en concreto, acarrea en sí mismo la esencia del sentido de la obra. Esta es la referencia a ese silencio del arte en Merleau-Ponty, un silencio lleno de sentido, un silencio que da que pensar la posibilidad de un silencio impredecible y abierto, así como la vida misma.

Ahondando en esto, por ejemplo, la obra no se puede entender en sí misma, ausente de todo tipo de espectador, no se puede comprender sola, sin que sea vista, espectada y performada. El hecho es simple, un cuadro o una narración literaria, no es una obra que subsista por sí misma, sin la necesidad de un espectador, no al menos en lo que respecta a su posibilidad de sentido. La interrelación que aquí se da es la que invita a retomar el gesto de quien ha creado la obra y esto se convierte en el todo de la obra siempre ligado a escuchar esta voz silenciosa. Espectador y pintura, novela y lector no se pueden concebir como entes diferentes que puedan, individualmente, hacer nacer el sentido. En torno a esta voz del silencio y su apertura a los sentidos posibles Merleau-Ponty nos dirá:

Habrá que llevar por tanto a una idea distinta de proyección, de acuerdo con la cual la palabra no sólo despierta en mis pensamientos anteriores, ya formados, sino que además me introduce en un movimiento de pens.amiento del que no hubiese sido capaz por mí solo, y me abre finalmente a significaciones extrañas (1971 175)

Esta idea de proyección distinta nos debe conducir a entender el lenguaje en su operación significante que nos quiere proponer Merleau-Ponty $(1971$ 80, 81). Movimientos de pensamiento, el diálogo entre el artista y el espectador en sus retribuciones silenciosas de sentido y las significaciones extrañas, son cualidades propias de este fenómeno de la voz del silencio propuesto por el filósofo francés. Debemos entender de esto que lo no dicho no significa una falta de razón, sino que más bien es ahí donde se construye el sentido artístico. Es la posibilidad misma de abrirnos a aquello que puede parecer extraño y familiar al mismo tiempo. La literatura no es sólo un despertar o una remembranza de pensamientos ya formados, o a meras palabras dichas. Tampoco significa formar un paso de una etapa de signos puros a otra etapa de puro sentido y de significación, sino que la originalidad de nuestro lenguaje se encuentra en sobrepasar la comunicación directa y abrirnos a la posibilidad de comprender el lenguaje que comunican los silencios literarios, de movernos en múltiples estados, en diferentes momentos y experiencias. Desde esto Merleau-Ponty nos señala que debemos considerar la palabra antes de que sea pronun- 
ciada, debemos considerarla sobre el fondo silencioso que la precede, que nunca deja de acompañarla, y sin el cual no diría nada (1971 80).

Por lo tanto, los silencios en el lenguaje artístico abren el despliegue para la significación y el sentido, ya que la propuesta merleau-pontiana evoca un silencio que debe ser reconocido como una característica fundamental del lenguaje. El trabajo merleau-pontiano nos pone frente a reconocer que en el mundo de la vida existen cuestiones que sobrepasan lo decible. Y la literatura, la pintura y su propio lenguaje artístico expresan más de lo que se desprende en concreto de la obra, y de cualquier consideración cuantitativa de la misma. Merleau-Ponty nos confronta con los silencios de lenguaje, porque percibe un símil directo de estos con la vida misma, en cuanto a que también comprende un carácter de lo que queda en entredicho, y tal entredicho es, a su vez, indeterminable, como aquello que se dice más allá o más acá de los hechos, o sea lo que se intuye o se insinúa a través de ellos. En La prose du monde, el filósofo señala:

Lo que hay de azaroso en la comunicación literaria, lo que hay de ambiguo e irreductible a la tesis en todas las grandes obras de arte, no radica en un defecto provisional de la literatura, cuya superación podría esperarse, sino que es el precio que hay que pagar por tener un lenguaje conquistador, que no se limite a enunciar lo que ya sabíamos, sino que nos introduzca en experiencias extrañas, en perspectivas que nunca serán las nuestras y nos desembarace al fin de nuestros prejuicios (1971 139).

Sobre esta cita desprendo tres ideas fundamentales: Primero, considerar que existen secciones de la comunicación literaria, específicamente referido al silencio literario que hemos desarrollado en nuestro análisis, que podrían considerarse como un azar sin intención concreta en la narración. Sin embargo, esto no representa, desde la perspectiva merleau-pontiana y dentro de la propuesta de nuestro escrito, una carencia del texto literario, sino que más bien se preserva como una de sus cualidades primordiales, ya que no son simples azares sin intención, sino que logran un espacio de sentido dentro de la obra. El carácter de ambigüedad irreductible del lenguaje artístico y de la obra literaria en general que nos menciona en la cita anterior Merleau-Ponty, nos otorga la posibilidad de una fuente de sentido que nos abre a la multiplicidad del mismo. En segundo lugar, considerar el carácter de ambigüedad del lenguaje literario en un modo peyorativo, o sea como aquello que nada nos puede proporcionar sobre la obra, sometería a reducción el lenguaje artístico, ya que ahogaría la propiedad de la literatura de exponernos a redescubrir aquellos caracteres propiamente ambiguos del mismo mundo de la vida. $Y$, en tercer lugar, la obra literaria no solamente nos introduce en aspectos cotidianos y mundanos de la experiencia vital, ni sólo a lo que conocemos, sino que supera lo 
conocido, siendo capaz de someternos en experiencias extrañas. La literatura puede ponernos a performar experiencias de las cuales, tal vez, no seriamos capaces en la vida cotidiana. Más aún, cuando Merleau-Ponty apunta, al final de la cita mencionada, a un lenguaje literario capaz de desembarazarnos al fin de nuestros prejuicios, podemos arriesgarnos a dar cuenta de la complejidad y la apertura con la cual puede trabajar la literatura. Las limitaciones culturales, en leyes, derecho o ética, pueden ser desbordadas por la literatura a tal modo, que podemos experimentarlas a través de la lectura literaria sin la necesidad de remitirnos a cuestiones de responsabilidad, culpa o arrepentimiento, no porque esta discusión no sea parte de lo literario, sino porque en el lenguaje artístico lo permite, y es esta una de sus cualidades fundamentales; la multiplicidad de la experiencia. Así, esta cualidad silenciosa del lenguaje literario se profundiza en lo siguiente: Las grandes obras de la literatura presentan momentos en que los personajes quedan sin palabras o los hechos son indescriptibles, momentos en que la palabra se agota para dar paso a momentos de silencio, momentos en que las palabras sobran o simplemente no alcanzan. Parece ser además que las grandes obras artísticas hacen de estos silencios sus cualidades expresivas fundamentales, hacen arte de aquello que en la existencia pareciera no tener una palabra, hablada o escrita, pudiera describir con exactitud lo que estos silencios ponen en manifiesto. Por ende, no es arriesgado postular que en la obra artística, en los silencios literarios, en las lecturas entre líneas, ahí en los espacios que parecieran vacíos, se erigen penas, alegrías, tristezas, euforias, dolores, padecimientos, risas etc., que no alcanzan a ser descritas sólo a través de palabras.

En la ficción literaria donde todo es posible, por lo que es fundamental para cualquier sociedad, esa exploración aguda y despiadada que promueven los artistas. ${ }^{9}$ Así la filosofía merleau-pontiana se dispone a un trato con lo artístico que va más allá de la tradicional ${ }^{10}$ propuesta teórica y objetiva de la misma. La denuncia

\footnotetext{
${ }^{9}$ En torno a esta idea podemos profundizar en el agudo análisis en torno al vínculo entre literatura y democracia llevado a cabo por J. Derrida. Afirma que esta posibilidad de la literatura de poder decirlo todo, y del derecho a decirlo todo no puede verse interrumpida bajo ningún sentido, e incluso liga este planteamiento a la posibilidad de la democracia. Sin literatura, por ejemplo, cuando se produce la censura de libros, la quema de los mismos por los gobiernos totalitarios, se manifiesta un claro síntoma de la pérdida de la democracia. Ambas cuestiones ligan su sentido y destino ( $c f$. Derrida 2011 61, 62).

${ }^{10}$ Sobre este respecto hacemos referencia a la filosofía tradicional desde la comprensión derridiana de la misma. J. Derrida concibe un pensamiento filosófico clásico (tradicional o metafísico) que abarca desde Platón hasta E. Husserl (e inclusive también M. Heidegger). Derrida señala que esta línea de pensamiento tradicional impone con violencia una búsqueda de significado últimos y tras-
} 
en este respecto ya se hace evidente: mientras el afán teórico y estricto de la filosofía tradicional se deshumaniza y pierde el contacto con el mundo de la vida, en orden a exponer ideas abstractas sobre variadas cuestiones humanas como la libertad, la amistad, la virtud, etc., pierde aquello que la literatura, en cambio, nos hace vivir y experimentar a través de su narración. Proponemos en la propuesta merleau-pontiana el nexo irrenunciable entre filosofía y literatura, un gesto que apunta a una necesaria consideración de la relevancia de cada discurso y de las cuestiones que cada uno, a su modo, pueden percibir y proponer frente al fenómeno existencial.

\section{Bibliografía.}

De Peretti, Cristina. Jacques Derrida, texto y deconstrucción. Barcelona: Antrophos, 1989.

Derrida, Jacques. Pasiones, la ofrenda oblicua. Buenos Aires: Amorrortu, 2011.

Gamboa, Leonardo. “La experiencia del lenguaje en la literatura: Anotaciones a la filosofía de Merleau-Ponty". Cuadernos De Filosofía Latinoamericana 26/92 (2005).

Merleau-Ponty, Maurice. Eloge de la Philosophie et autresessais. Paris: Gallimard, 1960.

- - - L'Oeiletl'esprit. Paris : Gallimard. 1964.

- - - La Prose du Monde. Paris : Gallimard, 1969.

- - - La prosa del mundo, trad. por Francisco Pérez Gutiérrez. Madrid: Taurus, 1971.

- - - El ojo y el espíritu, trad. Jorge Romero Brest. Barcelona: Paidós, 1986.

- - - Le doute de Cézanne, en Sense et non-sens. París: Gallimard, 1996. (primera publicación: Revista Fontaine 8/47 (1945): 13-33)

cendentes, buscando así representar, dar razón y sentar sobre suelo seguro sus suposiciones, o sea, dentro de un margen de garante de verdad. Para Derrida la violencia con la cual se imponen los discursos descansa en la búsqueda de fundamentos inmutables y en el anhelo de homogeneidad de los temas tratados por la filosofía (cf. De Peretti 1989 23, 32). 
- - - (2001) Signes. París, Gallimard.

- - - Elogio de la filosofía, seguido del lenguaje indirecto y las voces del silencio, trad. por Amalia Letelier. Buenos Aires: Nueva Visión, 2006. 